\title{
Phenolic Extracts from Vaccinium corymbosum L. Loaded in Microemulsions and Liposomes as Enhancers of Olive Oil Oxidative Stability
}

\author{
Nikolina Liovic ${ }^{1 *}$, Perica Bošković2 , Ivana Drvenica ${ }^{3}$, Anet Režek Jambrak ${ }^{4}$, Ana Marija Dropulič ${ }^{5}$, \\ Greta Krešićc ${ }^{1}$, Viktor Nedović, Branko Bugarski ${ }^{7}$, Zoran Zoric ${ }^{8}$, Sandra Pedisićc ${ }^{8}$, Tea Bilušićc
}

\author{
${ }^{I}$ Faculty of Tourism and Hospitality Management, University of Rijeka, Primorska 42 P.O. Box 97, 51410, Opatija, Croatia \\ ${ }^{2}$ Faculty of Science, University of Split, Ruđera Boškovića 33, 21000 Split, Croatia \\ ${ }^{3}$ Institute for Medical Research, University of Belgrade, Dr Subotica Starijeg 4, 11000 Belgrade, Serbia \\ ${ }^{4}$ Faculty of Food Technology and Biotechnology, University of Zagreb, Pierottijeva 6, 10000 Zagreb, Croatia \\ ${ }^{5}$ Faculty of Chemistry and Technology, University of Split, Ruđera Boškovića 35, 21000 Split, Croatia \\ ${ }^{6}$ Faculty of Agriculture, University of Belgrade, Nemanjina 6, 11080 Belgrade-Zemun, Serbia \\ ${ }^{7}$ Faculty of Technology and Metallurgy, University of Belgrade, Karnegijeva 4, 11000 Belgrade, Serbia \\ ${ }^{8}$ Faculty of Food Technology and Biotechnology, Centre for Food Technology and Biotechnology, \\ Petra Kasandrića 6, 23000 Zadar, Croatia
}

Key words: phenolics, blueberry, microemulsions, liposomes, antioxidant, ultrasound

Natural phenolic compounds are recognized as bioactive ingredients in food but can also have a role as effective alternatives to synthetic antioxidants in stability improvement of foods prone to oxidation, such as edible oils. This study aimed at the preparation and HPLC-DAD characterization of phenolic extracts from Vaccinium corymbosum L. (raw, pasteurized, freeze-dried and treated with high-intensity ultrasound), and at testing their antioxidant potential in the prevention of olive oil oxidation in the native state and encapsulated into microemulsions and liposomes systems. Water-in-oil structured microemulsions used in this study were prepared using mechanical, ultrasonic, and high pressure homogenization. Liposomes with the average size of $589.1 \pm 2.9 \mathrm{~nm}$ were produced with the proliposome method using commercially available phosphatidylcholine - Phospolipon 90G. The obtained results showed significant prolongation of the oxidative stability of extra virgin olive oil enriched with encapsulated blueberry phenolic extracts than with native phenolic extracts, regardless of the method used for blueberry processing. Phenolic extracts encapsulated in microemulsions had a stronger effect on the prolongation of olive oil oxidative stability in comparison with the extracts encapsulated in liposomes. The average prolongation rate of oxidative stability was $45.65 \%$ by phenolic extracts encapsulated in microemulsions prepared by mechanical homogenization $(\mathrm{p}=0.012)$, and $58.72 \%$ by microemulsions prepared by ultrasound homogenization $(\mathrm{p}=0.011)$. Phenolic extracts encapsulated in microemulsions prepared by high pressure homogenization had no effect on oil oxidative stability prolongation.

\section{INTRODUCTION}

Phenolics are the most common phytochemicals in a human diet that comprise a variety of compounds with a great diversity of structures and biological functions (antioxidant, anti-inflammatory, antimicrobial, anticancer, antiproliferative, antiatherosclerotic properties) [Giampieri et al., 2017; Haminiuk et al., 2012]. In addition to being considered as potent bioactive food ingredients they are also used to enhance the color, the flavor and the shelf life/stability of different foods prone to oxidation, such as edible oils [Aladedunye et al., 2014; Asnaashari et al., 2015].

Among plant-derived sources of natural phenolics, blueberries (Vaccinium corymbosum L.) are one of the richest sources per serving size [Pérez-Jiménez et al., 2010]. Compo-

\footnotetext{
* Corresponding Author: Tel.: +385 51294 707; Fax: +385 51292 945;

E-mail address: nikolina.liovic@fthm.hr (N. Liović)
}

sition, stability and biological activity of phenolics originated from blueberry were already reported [Nile \& Park, 2014; Rodríguez-Mateos et al., 2012]. Specifically, blueberries are characterized by a high content of anthocyanins that have been associated with a reduced risk of hypertension and myocardial infarction [Afrin et al., 2016], a preventive effect on metabolic syndrome [Basu \& Lyons, 2012], beneficial effects on lipid profiles, and an inhibitory effect on atherosclerosis development [Huang et al., 2016]. The beneficial health effects of phenolic compounds depend not only on food intake but also on their stability which can vary due to the used post-harvest processing methods and the storage conditions of blueberry fruits [Michalska \& Lysiak, 2015]. For instance, conventional fruit processing methods, such as pasteurization, which are still most commonly used, provide microbiological stability and longer shelf-life, but, on the other hand, their application can provoke the degradation of phenolic compounds. Therefore, researchers are nowadays more fo- 
cused on the usage of novel food processing technologies that are able to preserve valuable phenolic compounds, such as freeze-drying, pulsed electric fields, high-intensity ultrasound, and high pressure processing [Barba et al., 2017; Sablani et al., 2011].

Apart from the conventional and modern processing technologies used to preserve phenolics, the use of various encapsulation methods has become extremely important for further protection of these unstable compounds and prolongation of their biological activities. In that sense, the use of different encapsulation techniques (spray drying, coacervation, emulsions, liposomes, micellae, nanoparticles, freeze-drying, cocrystallization) in combination with phenolic extracts or pure phenolic compounds has been reported so far [Chatzidaki et al., 2015; Drvenica et al., 2017]. The use of emulsions is considered as one of the most promising and rapidly developing tools in the food industry due to their high-efficiency encapsulation rate, the maintenance of chemical stability of a targeted compound, and its controlled release [Lu et al., 2016]. The mean droplet diameter of emulsions within food systems is typically somewhere between $100 \mathrm{~nm}$ and $100 \mu \mathrm{m}$. If dispersed phase droplets sizes are less than $100 \mathrm{~nm}$, these (nano)emulsions are referred to as microemulsions [McClements, 2012]. Microemulsions, in particular, have beneficial properties that are suitable for designing functional foods due to their optical clarity, thermodynamical stability (high stability to gravitational separation, flocculation, and coalescence), and improved absorption, stability and bioavailability of bioactive components [Xu et al., 2017]. Liposomes are also interesting encapsulation systems, which have been widely used in the pharmaceutical and food industries. Due to the amphiphilic nature of the phospholipid bilayer, they have the ability to carry a variety of lipophilic and hydrophilic bioactive compounds. In recent years, liposomes have been used for the encapsulation of different phenolic compounds, such as hibiscus extract [Gibis et al., 2014], resveratrol [Isailović et al., 2013], green tea catechin and epigallocatechin gallate [Rashidinejad et al., 2014], as well as curcumin [Gómez-Mascaraque et al., 2017]. Gortzi et al. [2008] have proven that the antioxidant and antimicrobial activity of the Myrtus communis extract encapsulated in liposomes was higher compared to the extract in its pure form.

Despite the benefits arising from literature data on different processing methods used prior to the extraction of phenolics and their subsequent protection by encapsulation, there is a lack of such studies performed on blueberry fruits. Thus, the major objectives of this study were: (1) to determine and to compare the phenolic profile of blueberry extracts obtained from fruits in raw state and after pasteurization, freeze-drying, and high-intensity ultrasound by HPLC-DAD technique; (2) to prepare microemulsions using mechanical, ultrasound and high pressure homogenization, to characterize them and to encapsulate blueberry phenolic extracts into microemulsions; (3) to prepare and to characterize liposomes and to encapsulate blueberry phenolic extracts into liposome systems; and finally (4) to determine the effect of native and encapsulated blueberry phenolic extracts on olive oil oxidative stability by a Rancimat instrument.
TABLE 1. Experimental design of ultrasound treatment.

\begin{tabular}{l|c|c|c}
\hline Sample & $\begin{array}{c}\text { Amplitude } \\
(\%)\end{array}$ & $\begin{array}{c}\text { Treatment time } \\
(\mathrm{min})\end{array}$ & $\begin{array}{c}\mathrm{E} \\
(\mathrm{J})\end{array}$ \\
\hline A1 & 100 & 6 & 26621 \\
A2 & 50 & 6 & 16154 \\
A3 & 50 & 9 & 21385 \\
A4 & 100 & 9 & 33623 \\
A5 & 75 & 6 & 19904 \\
A6 & 50 & 3 & 8625 \\
A7 & 75 & 6 & 20391 \\
A8 & 75 & 3 & 11101 \\
A9 & 100 & 3 & 13902 \\
A10 & 75 & 6 & 19899 \\
A11 & 75 & 9 & 28762 \\
\hline
\end{tabular}

\section{MATERIAL AND METHODS}

\section{Sample preparation}

Fresh blueberry samples were purchased in a local grocery store. One part of the samples was taken for dry matter determination and the other was blended into a blueberry puree. Part of the blueberry puree was separated and stored as a fresh control sample at $-20^{\circ} \mathrm{C}$ under nitrogen atmosphere. The other part was subjected to subsequent processing. Total dry matter and moisture content were determined gravimetrically according to the AOAC 930.04 method by drying the samples in a thermal oven (Memmert, UF30, Schwabach, Germany) at $105^{\circ} \mathrm{C}$ until a constant weight has been achieved [Helrich, 1990].

\section{Ultrasound treatment}

High intensity ultrasound treatment was performed with an ultrasonic processor SONICATOR S-4000 (Misonix Sonicators, Newtown, CT, USA) with a probe diameter of $19.1 \mathrm{~mm}$, at a frequency of $20 \mathrm{kHz}$. Blueberry puree $(100 \mathrm{~mL})$ was placed in a beaker $(200 \mathrm{~mL})$, which was used as a treatment vessel. Ultrasonication was carried out for 3, 6 and 9 min at an amplitude of 50, 75, and 100\%. The experiment was designed in STATGRAPHICS Centurion (Stat Point Technologies, Inc., Warrenton, VA, USA) software using Multi-Factor Categorical Design. The experiment consisted of 11 experimental trials and one of them was replicated to get a good estimate of a potential experimental error (Table 1). Repetition experiments were carried out after other experiments followed by the order of runs designed by the program. After all treatments, the samples were stored at $-20^{\circ} \mathrm{C}$.

\section{Freeze drying}

Freeze drying was carried out in a freeze dryer (Labconco, Kansas City, USA) at a temperature of $-55^{\circ} \mathrm{C}$. Freeze-dried blueberries were finely ground into a powder and stored in a dry and dark place at the temperature below $20^{\circ} \mathrm{C}$. 


\section{Pasteurization}

Pasteurization was performed in a thermal oven (Memmert, UF30, Schwabach, Germany) at the temperature of $80^{\circ} \mathrm{C}$ for $5 \mathrm{~min}$ after which the sample was cooled down in cold water. The extraction of phenolics was done immediately after the pasteurization treatment.

\section{Phenolics extraction and determination of total phenolic content}

Extraction of phenolic compounds from blueberry samples was carried out according to the method described by Dragović-Uzelac et al. [2010]. Briefly, $5 \mathrm{~g}$ of blueberry puree and $0.5 \mathrm{~g}$ of freeze-dried blueberry powder were weighed and extracted using $20 \mathrm{~mL}$ of $80 \%$ (v/v) aqueous ethanol for 20 min under nitrogen atmosphere and filtered through filter paper Whatmann no. 40 (Whatmann International Ltd., Kent, UK) using a Büchner funnel. The extraction of the residue was repeated and the filtrates were combined and adjusted to $50 \mathrm{~mL}$ in a volumetric flask with $80 \%$ (v/v) aqueous ethanol.

The total phenolic content (TPC) in extracts was determined using the Folin-Ciocalteau reagent [Singleton \& Rossi, 1965], and results were expressed as gallic acid equivalents (GAE) per $100 \mathrm{~g}$ of fresh weight (fw). All determinations were run in triplicate.

\section{Analysis of phenolic compounds using HPLC-DAD}

Chromatographic separation was performed using an HPLC instrument with Agilent 1260 Infinity quaternary LC system (Agilent Technologies, Santa Clara, CA, USA) equipped with a photodiode array detector (PDA), an automatic injector, and ChemStation software. Extracts were previously filtered through a $0.45-\mu \mathrm{m}$ pore size membrane filter (Macherey-Nagel GmbH \& Co. KG, Düren, Germany). The separation of compounds was performed on a Nucleosil 100-5C18, $5 \mu \mathrm{m}(250 \mathrm{~mm} \times 4.6 \mathrm{~mm}$ i.d.) column (Macherey-Nagel GmbH \& Co. KG, Düren, Germany). Solvent composition and gradient conditions were as previously described by Zorić et al. [2014].

For gradient elution, mobile phase A contained 3\% of formic acid in water $(\mathrm{v} / \mathrm{v})$, while solution $\mathrm{B}$ contained $3 \%$ of formic acid in $80 \%$ acetonitrile $(\mathrm{v} / \mathrm{v})$. The elution program was as follows: 0-28 min 0\% B, 28-35 min 25\% B, 35-40 min 50\% B, $40-45 \mathrm{~min} 80 \% \mathrm{~B}$, and for the last $10 \mathrm{~min}$ again $0 \% \mathrm{~B}$ at a flow rate of $0.8 \mathrm{~mL} / \mathrm{min}$. The injection volume was $5 \mu \mathrm{L}$. Calculation of the concentrations was based on the external standard method and the compounds were identified by comparing their retention times and absorption spectra with those of the authentic standards (anthocyanins were identified at $520 \mathrm{~nm}$, phenolic acid at $280 \mathrm{~nm}$ and flavonol glycoside at $360 \mathrm{~nm}$ ).

All anthocyanin standards, delphinidin-3-glucoside (D-3-G), cyanidin 3-glucoside (C-3-G), petunidin 3-glucoside (Pt-3-G), peonidin 3-glucoside (Pn-3-G), and malvidin 3-glucoside (M-3-G) were prepared as stock solutions in acidified methanol ( $1 \%$ of formic acid in methanol, v/v) at a concentration of $100 \mathrm{mg} / \mathrm{L}$. Working standard solutions were prepared by diluting the stock solution to yield five concentrations in a range from 20 to $100 \mathrm{mg} / \mathrm{L}$.

Standards of quercetin-3-glucoside (Q-3-G) and chlorogenic acid (CA) were prepared as stock solutions in etha- nol/water (8:2, v/v) at the following concentrations: Q-3-G $400 \mathrm{mg} / \mathrm{L}$ and CA $52 \mathrm{mg} / \mathrm{L}$. Working standard solutions were prepared by diluting the stock solution to yield five concentrations in the range from 80 to $400 \mathrm{mg} / \mathrm{L}$ for $\mathrm{Q}-3-\mathrm{G}$ and from 10.4 to $52 \mathrm{mg} / \mathrm{L}$ for CA. The results were expressed in mg per $100 \mathrm{~g}$ of fresh weight, as mean value \pm standard deviation $(\mathrm{N}=2$ replicates).

\section{Preparation of microemulsions}

Two microemulsion samples (ME-1 and ME-2) were prepared using the best combination of extra virgin olive oil as an oil phase at the percentage obtained from preliminary studies by diluting the combination of oil and a surfactant/cosurfactant mixture with water using a magnetic stirrer and an Ultra-Turrax T25 Homogenizer (IKA Labortechnik, Staufen, Germany) for $5 \mathrm{~min}$. The surfactant to cosurfactant ratio (i.e. Tween 80 to ethanol) was 9:1 (w/w). The mixture turned from turbid through opaque to a translucent yellow mixture, forming a microemulsion. The obtained microemulsions contained: $70 \%(\mathrm{w} / \mathrm{w})$ of the surfactant/cosurfactant mixture, $20 \%$ (w/w) of extra virgin olive oil, and $10 \%$ of aqueous phase in the case of ME-1 sample; and 70\% (w/w) of the surfactant/cosurfactant mixture, $10 \%(\mathrm{w} / \mathrm{w})$ of extra virgin olive oil, and $20 \%$ of aqueous phase in the case of ME-2 sample. Apart from the preparation of microemulsions by mechanical homogenization, a previously mentioned mixture containing water, olive oil, Tween 80 and ethanol was treated in a Ultrasonic Lab Homogenizer UP200S (Hielscher Ultrasonics GmbH, Teltow, Germany) for $5 \mathrm{~min}$. The frequency was $20 \mathrm{kHz}$ with an amplitude of $70 \%$. The third way to prepare emulsion systems was to use a High-Pressure Homogenizer (EmulsiFlex-C3, Avestin Europe GmbH, Mannheim, Germany). Three cycles under 1000 bar were applied with the constant flow at $50 \mathrm{~mL} / \mathrm{min}$.

\section{Preparation of liposomes}

Liposomes with phenolic extracts were prepared using the proliposome method as described by Pravilovic et al. [2015]. This method, easy scalable for industrial application, implies the initial formation of a proliposome mixture containing lipid, ethanol, and water, which is eventually converted into liposomes by a simple dilution step [Perrett et al., 1991]. Commercially available soy lecithin Phospholipon 90G (Phospholipid GmbH, Köln, Germany), which consists of phosphatidylcholine (min. 94\%), was used for the preparation of liposomes. Namely, the mixture of Phospholipon 90G with an adequate amount of ethanol and water (1:0.8:2, w/w/w) was heated up to $60^{\circ} \mathrm{C}$ in a sealed beaker with continuous stirring at $800 \mathrm{rpm}$ until a homogenous dispersion has been obtained. After cooling the mixture down to $25^{\circ} \mathrm{C}$, a small portion of phenolic extract was added to the dispersion while stirring at $800 \mathrm{rpm}$ during the next $30 \mathrm{~min}$ to obtain the final liposomal formulation. The ratio between phenolic extracts and Phospholipon 90G used in liposomes was 1:10 (w/w).

\section{Characterization of microemulsions and liposomes}

Droplet size, polydispersity index, and zeta potential determination

The droplet size, polydispersity index (PDI), and zeta potential of microemulsions and liposome samples were 
measured with photon correlation spectroscopy using Zetasizer Nano ZS (Malvern Panalytical Ltd, Malvern, UK). Each sample was measured three times at the room temperature and the averages were taken as a result. Furthermore, the liposome samples were diluted by 1000 with ultra-pure water before the measurements to avoid multiple scattering effects. Physical stability of the prepared liposomes stored at $+4^{\circ} \mathrm{C}$ was monitored through repeated photon correlation spectroscopy measurements after 7, 14, and 21 days.

\section{Liposome encapsulation efficiency}

The encapsulation efficiency in liposomes was calculated based on the determination of TPC through centrifugal separation of un-encapsulated phenolic extract from loaded liposomes, as described by Isailović et al. [2013].

\section{Viscosity, conductivity, and surface tension measurements}

The viscosity of microemulsion samples was measured at $25^{\circ} \mathrm{C}$ with a Brookfield viscometer (LVDV-E, Brookfield Engineering Laboratories, Middleboro, MA, USA) using spindle no. 61 . with a shear rate of $30 \mathrm{rpm}$. The electrical conductivity and surface tension of microemulsion samples were also measured at $25^{\circ} \mathrm{C}$ with a conductivity meter (inoLab 7310 , WTW GmbH, Weilheim, Germany) using conductivity cells with a cell constant of 1.0 and a tensiometer (SIGMA 703D, Biolin Scientific Oy, Espoo, Finland) using the ring method, respectively. The conductivity of liposome samples was determined using a Zetasizer Nano ZS apparatus (Malvern Panalytical Ltd, Malvern, UK). All measurements were performed in triplicate.

\section{Physical stability study}

The physical stability of microemulsions (ME-1 and ME-2) was studied with regard to the thermal stability and centrifugation effects. Microemulsions were kept at different temperatures $\left(4^{\circ} \mathrm{C}, 25^{\circ} \mathrm{C}\right.$, and $\left.35^{\circ} \mathrm{C}\right)$ and observed for phase separation, precipitation or flocculation. Also, microemulsions were centrifuged (Sorvall RC 5B Superspeed Centrifuge, Dupont, Newton, USA) at $8000 \mathrm{rpm}$ for $20 \mathrm{~min}$ at the temperature of $25^{\circ} \mathrm{C}$ and inspected for any change in their homogeneity.

\section{Evaluation of the antioxidant potential of phenolic extracts with the Rancimat method}

The oxidative stability of extra virgin olive oil enriched with phenolic extracts from blueberries (in the native form and encapsulated in microemulsions and liposomes) was evaluated using a Rancimat 743 instrument (Metrohm, Herisau, Switzerland) to monitor the progress of accelerated oxidation at the temperature of $120^{\circ} \mathrm{C}$. The olive oil samples $(3 \mathrm{~g})$ were enriched with $0.2 \mathrm{~g}$ of phenolic extracts and with $0.4 \mathrm{~g}$ of microemulsions and liposomes containing phenolic extracts (2:1 ratio).

The samples were tested at a temperature of $120^{\circ} \mathrm{C}(\Delta \mathrm{T}=$ $1.4^{\circ} \mathrm{C}$ ) with a constant air flow of $20 \mathrm{~L} / \mathrm{h}$. The conductivity was measured as a function of time and the results are expressed as a prolongation of the induction time (in hours). All determinations were performed in triplicate, and the results are presented as mean value \pm standard deviation.

\section{Statistical analysis}

Data analyses were performed using MedCalc Statistical Software version 14.8.1 (MedCalc Software, Ostend, Belgium; http://www.medcalc.org; 2014). Since the data could not meet the criteria of variance homogeneity (Levene's test) and normal distribution (determined with Shapiro-Wilks test), the analysis was performed with Kruskal-Wallis test. In all analyses, $\mathrm{p}$-values of $<0.05$ were considered statistically significant.

\section{RESULTS AND DISCUSSION}

\section{Influence of different processing treatments on blueberry phenolic profile and TPC}

To the best of our knowledge, this study is the first report that compares the phenolic profile and TPC of blueberry extracts obtained from raw plant material, and from plant material treated by conventional (pasteurization) and modern processing technologies (freeze-drying, high-intensity ultrasound).

Table 2 shows contents of individual anthocyanins, flavonol glycosides, and chlorogenic acid in different blueberries extracts. As expected, anthocyanins were the most abundant phenolic compounds and five anthocyanidin glycosides were identified. The predominant anthocyanidin glycosides in fresh (A0), freeze-dried (AL), and in all ultrasound-treated samples (A1-A11) were malvidin and delphinidin glycosides that together accounted for almost $80 \%$ of all detected anthocyanins. The obtained results are in accordance with previously reported data [Neveu et al., 2010]. In the pasteurized sample (AP), due to thermal degradation, only malvidin and peonidin glycosides were detected and total anthocyanin content was reduced by almost $80 \%$. Total anthocyanin content calculated as the sum of all individual anthocyanidin glycosides was lower in comparison to other studies [Može et al., 2011; Rodríguez-Mateos et al., 2012]. The content of chlorogenic acid in all samples was remarkably lower and that of flavonol glycosides was higher than previously reported data [Može et al., 2011; Neveu et al., 2010; Rodríguez-Mateos et al., 2012]. These differences may be attributed to the inherent variability in the plant material due to growing location and conditions but also because of different methodologies used to quantify phenolic compounds.

Concerning the TPC among different extracts (Table 3), the obtained results indicate that the freeze-dried extract had a 33\% higher phenolic content as compared to the raw plant material (fresh, untreated puree). This is in accordance with the findings of Sablani et al. [2011] who reported improved retention of phytochemicals after freeze-drying treatment. Freeze-drying may lead to a higher extraction efficiency due to the formation of ice crystals which cause the rupturing of cell structure and thus better solvent access during the extraction [Keinänen \& Julkunen-Tiitto, 1996]. Brownmiller et al. [2008] investigated the effect of thermal treatment on blueberry products and found a significant loss of anthocyanins (28 to 95\%), which is in accordance with results of this study. Pasteurized blueberry puree had a significantly lower amount of total phenolics as compared to the raw sample due 


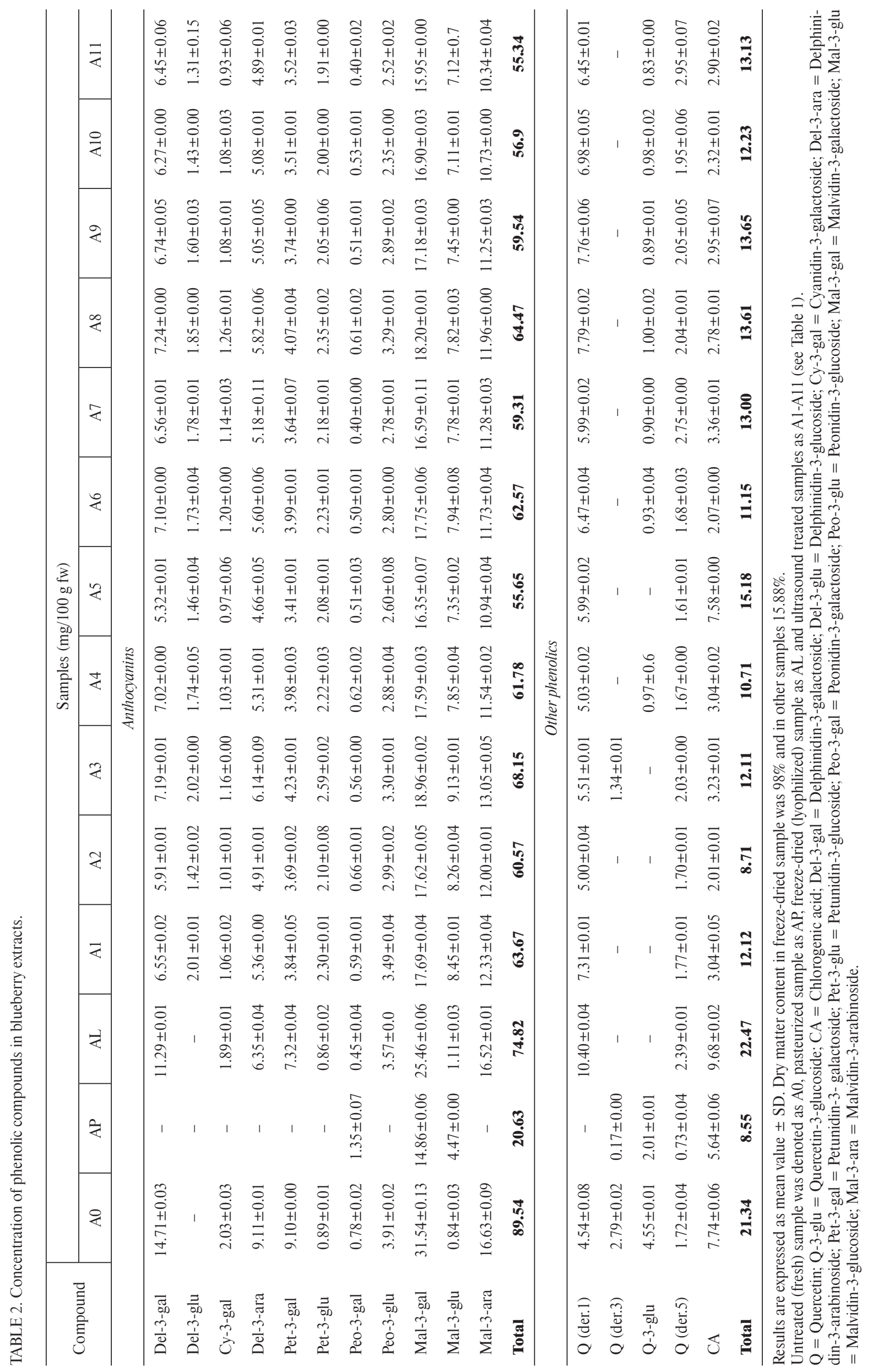


TABLE 3. Total phenolic content (TPC) of blueberry extracts.

\begin{tabular}{|c|c|c|c|}
\hline \multirow{2}{*}{ Sample } & \multicolumn{3}{|c|}{ TPC (mg GAE/100 g fw) } \\
\hline & Median & Min & Max \\
\hline A0 & $312.58^{\mathrm{b}}$ & 302.02 & 338.98 \\
\hline $\mathrm{AP}$ & $276.67^{\mathrm{a}, \mathrm{c}, \mathrm{d}, \mathrm{f}, \mathrm{i}, \mathrm{l}, \mathrm{m}, \mathrm{n}}$ & 197.47 & 288.28 \\
\hline $\mathrm{AL}$ & $417.54^{\text {b,d,e,g, }, \mathrm{h}, \mathrm{j}, \mathrm{k}, \mathrm{m}}$ & 391.87 & 419.25 \\
\hline $\mathrm{A} 1$ & $327.36^{\mathrm{b}, \mathrm{c}}$ & 280.90 & 333.70 \\
\hline $\mathrm{A} 2$ & $284.06^{\mathrm{cf}, \mathrm{i}, \mathrm{l}}$ & 274.56 & 287.23 \\
\hline A3 & $321.02^{\mathrm{be}, \mathrm{h}}$ & 315.74 & 341.09 \\
\hline A4 & $290.40^{c}$ & 285.12 & 308.35 \\
\hline A5 & $289.34^{\mathrm{cff,i}}$ & 268.22 & 292.51 \\
\hline A6 & $332.64^{b, e, h, j}$ & 325.25 & 332.64 \\
\hline A7 & $284.06^{\mathrm{c}, \mathrm{i}}$ & 254.50 & 326.30 \\
\hline A8 & $307.30^{c}$ & 283.01 & 319.97 \\
\hline A9 & $355.87^{\mathrm{bee}}$ & 279.84 & 365.38 \\
\hline $\mathrm{A} 10$ & $321.02^{\mathrm{b}, \mathrm{c}}$ & 283.01 & 350.59 \\
\hline A11 & $325.25^{\mathrm{b}}$ & 295.68 & 326.30 \\
\hline $\mathrm{p}$-value & 0.041 & & \\
\hline
\end{tabular}

Medians compared with Kruskal Wallis test. Statistically significant differences $(\mathrm{p}<0.05)$ from: ${ }^{\mathrm{a}} \mathrm{A} 0,{ }^{\mathrm{b}} \mathrm{AP},{ }^{\mathrm{c}} \mathrm{AL},{ }^{\mathrm{d}} \mathrm{A} 1,{ }^{\mathrm{e}} \mathrm{A} 2,{ }^{\mathrm{f}} \mathrm{A} 3,{ }^{\mathrm{g}} \mathrm{A} 4,{ }^{\mathrm{h}} \mathrm{A} 5,{ }^{\mathrm{i}} \mathrm{A} 6,{ }^{\mathrm{j}} \mathrm{A} 7$, kA8, 'A9, ' ${ }^{\mathrm{A}} \mathrm{A} 10,{ }^{\mathrm{n}} \mathrm{A} 11$.

$\mathrm{A} 0=$ Untreated (fresh) sample; $\mathrm{AP}=$ pasteurized sample; $\mathrm{AL}=$ freeze-dried (lyophilized) sample; A1-A11 = ultrasound treated samples (see Table 1).

to thermal sensitivity of phenolics. However, another study has shown that pasteurization significantly decreased only anthocyanin content but not TPC which could be explained by condensation reactions between anthocyanins and other polymeric compounds resulting in the formation of polymerized phenolic compounds that can be detected with the Fo-
lin-Ciocalteau reagent [Casati et al.2017]. In addition, an interesting study conducted by Howard et al. [2016] showed that stability of anthocyanins during pasteurization can be achieved with previous acidification of juice samples to $\mathrm{pH}$ 2.1. No significant changes in TPC were observed after ultrasound treatments, however, the recovery of phenolics mostly increased after the shortest treatment ( $3 \mathrm{~min}$ ) at amplitudes of 50 and $100 \%$. A slight decrease in total phenolic content was found at higher temperatures at the end of the process and this effect was more pronounced with longer treatments time (6 and $9 \mathrm{~min}$ ). Overall, the obtained results showed that none of the ultrasound treatments had negative effects on the TPC of the blueberry fruits. As previous studies showed, ultrasonic treatments can ensure the microbial safety of foods, while their influence on phenolic compounds is minimal [Golmohamadi et al., 2013].

\section{Characterization of microemulsions and liposomes}

For the characterization of microemulsions and liposome systems, particle size as well as particle size distribution represent indispensable factors due to their effect on the emulsification properties, viscosity, and stability.

Emulsion systems used in this study were prepared by mechanical, ultrasound and high pressure homogenization to obtain microemulsions with enhanced stability. Regardless of the preparation technique, the microemulsion samples had a droplet size distribution with a PDI value of $0.683 \pm 0.015$ and droplet size of $50.43 \pm 8.17 \mathrm{~nm}$ for microemulsion 1 (ME-1) and a PDI value of $0.722 \pm 0.023$ and droplet size of $9.87 \pm 1.63 \mathrm{~nm}$ for microemulsion 2 (ME-2), which indicates that a stable microemulsion was formed. Focusing on size distribution by intensity in Figure 1, large peaks around $1000 \mathrm{~nm}$ may be caused by few large particles (commonly called "dust") which are also the main reason of higher PDI. A confirmation of these previous statements is the absence of these peaks in size distribution by number. a) $\mathrm{ME}-1$

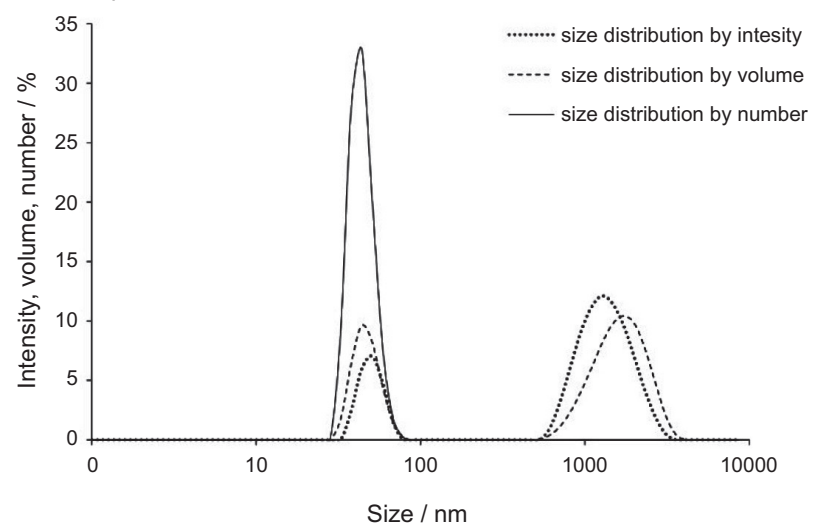

b) ME-2

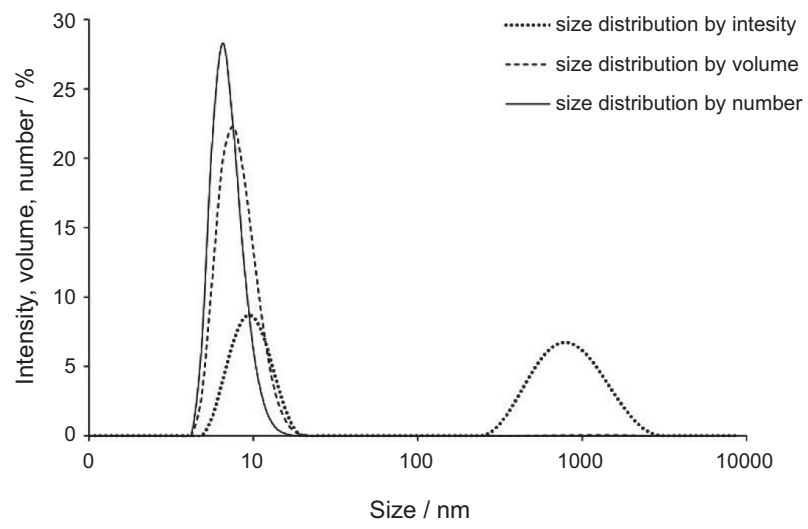

\begin{tabular}{|c|c|c|c|c|c|}
\hline Formulation & Refractive index & $\begin{array}{l}\text { Zeta-potential } \\
(\mathrm{mV})\end{array}$ & $\begin{array}{l}\text { Conductivity } \\
(\mathrm{ms} / \mathrm{cm})\end{array}$ & $\begin{array}{l}\text { Surface tension } \\
\qquad(\mathrm{nM} / \mathrm{m})\end{array}$ & $\begin{array}{l}\text { Viscosity } \\
\text { (cP) }\end{array}$ \\
\hline ME-1 & 1.4616 & -7.16 & 0.0352 & 32.20 & 907 \\
\hline ME-2 & 1.4510 & -2.11 & 0.0280 & 31.87 & 1105 \\
\hline
\end{tabular}

FIGURE 1. The droplet size distribution by intensity, volume, and number for: a) ME-1 and b) ME-2 microemulsion, as well as a refractive index, zeta-potential, conductivity, surface tension, and viscosity. Composition of ME-1 and ME-2 is provided in Materials and Methods section. 
The obtained results are in accordance with the study by Jafari et al. [2006], who concluded that emulsification required optimal conditions for both methods beyond which the emulsion sizes would either increase or have little change with further processing. It is well known that there is a strong correlation between the specific structure of the microemulsion systems and their electrical conductive behavior, where phase systems ("oil in water" or "water in oil") of the microemulsions were determined by measuring specific conductivity [Eicke et al., 1989]. In this study, microemulsion formulations had a specific conductivity of $0.035 \mathrm{mS} / \mathrm{cm}$ for ME- 1 and $0.028 \mathrm{mS} / \mathrm{cm}$ for ME-2, which indicates the "water in oil" structure of microemulsions. Also, "water in oil" structure of microemulsions is confirmed with color tests. The mean viscosity of formulations was $907 \mathrm{cps}$ for ME-1 and $1105 \mathrm{cps}$ for ME-2. The highest viscosity was found for ME-2, which indicates a possible change from "water in oil" to a bicontinuous structure. The surface tension of the formulations was $32.20 \mathrm{mN} / \mathrm{m}$ for ME-1 and $31.67 \mathrm{mN} / \mathrm{m}$ for ME-2. It can be concluded that both samples had a "water-in-oil" structure because the surface tension and refractive index values were very close to the values of an oil continuous phase. The visual examination experiment was carried out over a period of 6 months in weekly intervals for the first 3 months and monthly intervals for the subsequent months. The visual observation showed no evidence of phase separation or any precipitation or flocculation. These samples also revealed no sign of phase separation under centrifugation stress at $8000 \mathrm{rpm}$ for $20 \mathrm{~min}$. The centrifugation tests showed that microemulsions remained homogenous without any phase separation, which points to their good physical stability.

The two produced microemulsions, ME-1 and ME-2, were used as a "premix" for further investigation on the blueberry phenolic extract incorporation by an appropriate method in a portion of $30 \%(\mathrm{v} / \mathrm{v})$. Interestingly, the microemulsion containing phenolic extracts from blueberries had nearly

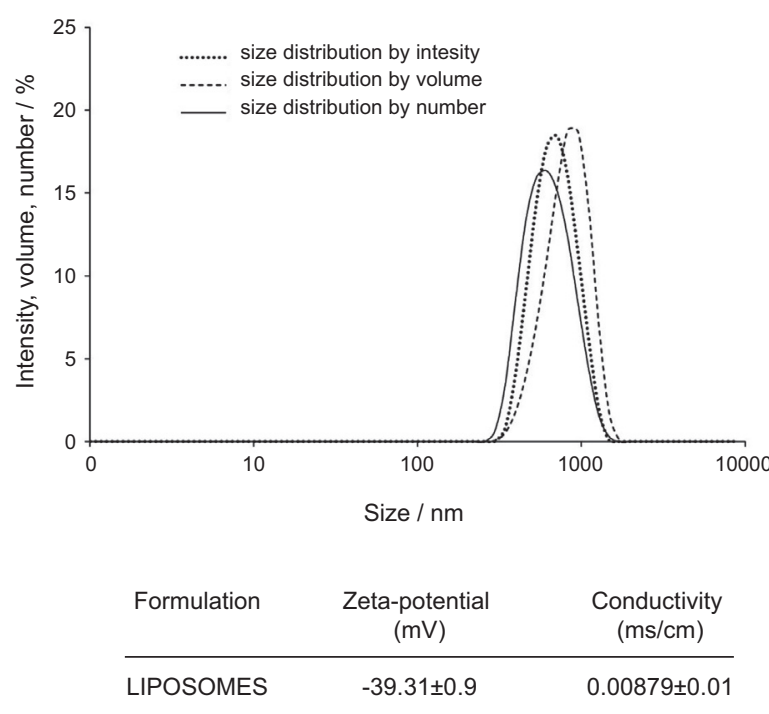

FIGURE 2. The size distribution by intensity, volume, and number of liposomes used in the study, as well as the zeta-potential and conductivity. the same size distribution as the one without extracts (data not shown). Incorporation of various phenolic compounds in microemulsions results in small changes in the apparent hydrodynamic diameter of the aqueous droplets [Chatzidaki et al., 2015]. This result was also confirmed by Jafari et al. [2006] that a critical point above which the emulsions become "over-processed" exists and that only slight effect on emulsion droplet size can be achieved from "premix" (ME-1 and ME-2) to final emulsions. This outcome was established even when different methods were combined ( mechanical homogenization for premix production and high-pressure homogenization for final emulsion formation), as shown by the study of Juttulapa et al. [2017].

The average size of liposomes (z-average) used in this study was $589.1 \pm 2.9 \mathrm{~nm}$. The size distribution of liposomes shown in Figure 2 by intensity, volume, and number $\%$, revealed very monodispersed distribution with a PDI of $0.172 \pm 0.019$. This result was in agreement with a study of Isailović et al. [2013], where in a comparison of a few different methods for the preparation of liposome, the proliposome method gave the lowest PDI value (below 0.2.), confirming once more its efficacy and relevance for industrial application. Liposome vesicles had a negative surface charge with mean zeta potential of $-39.1 \pm 0.9$, suggesting good electrostatic stabilization of dispersion against aggregation [Isailović et al., 2013; Rashidinejad et al., 2014]. This was also confirmed by the stability test results, where the mean diameter of liposomes did not change by more than $9 \%$ during three weeks of storage at $+4^{\circ} \mathrm{C}$ (data not shown). Liposomes containing phenolic extracts from blueberries had nearly the same size as liposomes without extracts. This outcome is consistent with the results reported by Gibis et al. [2014] who encapsulated hibiscus extract in soy lecithin liposomes. Furthermore, loaded liposomes showed no significant change of mean zeta potential, indicating that phenolics are located inside the vesicles, most likely via hydrogen bonding between polar head groups of liposomes and phenolics, and hydrophobic interactions of hydrophobic moieties of the phenolics and the fatty acid tails of phospholipids in liposomes [Gibis et al., 2012]. The encapsulation efficiency of the produced liposomal formulation was $70.5 \pm 0.8 \%$, which is very similar to other reports of lecithin liposomes loading green tea and hibiscus extracts [Gibis et al., 2014; Rashidinejad et al., 2014].

\section{The effect of native and encapsulated blueberry phenolic extracts on the oxidative stability of edible oil}

The use of antioxidants in the food industry has an important role since oxidation of edible oils is one of the major challenges. There are few studies that evaluated the effect of fruit phenolic compounds on the prolongation of the oxidative stability of edible oils [Aladedunye et al., 2014; Asnaashari et al., 2015]. However, there is a lack of studies focused on the use of microemulsions and/or liposomes to enhance the effect of phenolic compounds in the prolongation of the edible oil oxidative stability. In that sense, this is the first comparative study about the effect of native and encapsulated blueberry phenolic extracts on the oxidative stability of extra virgin olive oil measured with the Rancimat apparatus. Extra virgin olive oil was used as a matrix because it represents one of the healthiest 
TABLE 4. The prolongation of the lag phase of the oxidative stability of olive oil (in hours) with native phenolic extracts from Vaccinium corymbosum L. and loaded in microemulsions (ME-1 and ME-2) and liposomes.

\begin{tabular}{|c|c|c|c|c|c|c|}
\hline \multirow{2}{*}{ Sample } & \multirow{2}{*}{ Phenolic extracts } & \multicolumn{2}{|c|}{ ME-1 } & \multicolumn{2}{|c|}{ ME-2 } & \multirow{2}{*}{ Liposomes } \\
\hline & & $\begin{array}{c}\text { Mechanical } \\
\text { homogenization }\end{array}$ & $\begin{array}{c}\text { Ultrasound } \\
\text { homogenization }\end{array}$ & $\begin{array}{c}\text { Mechanical } \\
\text { homogenization }\end{array}$ & $\begin{array}{c}\text { Ultrasound } \\
\text { homogenization }\end{array}$ & \\
\hline A0 & 0.00 & $3.90 \pm 0.31^{*}$ & $3.45 \pm 0.20^{*}$ & $1.20 \pm 0.06$ & $5.78 \pm 0.28^{*}$ & $3.05 \pm 0.11^{*}$ \\
\hline $\mathrm{AP}$ & $0.62 \pm 0.13^{*}$ & $0.78 \pm 0.31$ & $2.77 \pm 0.13^{*}$ & $4.62 \pm 0.33^{*}$ & $5.76 \pm 0.17^{*}$ & $8.87 \pm 0.20^{*}$ \\
\hline $\mathrm{AL}$ & 0.00 & $2.88 \pm 0.06^{*}$ & $7.42 \pm 0.07^{*}$ & $1.99 \pm 0.20^{*}$ & $5.55 \pm 0.06^{*}$ & $3.63 \pm 0.14^{*}$ \\
\hline $\mathrm{A} 1$ & $0.46 \pm 0.34^{*}$ & $3.46 \pm 0.07^{*}$ & $9.89 \pm 0.21^{*}$ & $1.39 \pm 0.07^{*}$ & $6.86 \pm 0.23^{*}$ & $2.27 \pm 0.21$ \\
\hline A2 & $0.94 \pm 0.25^{*}$ & $4.72 \pm 0.31^{*}$ & $10.29 \pm 0.16^{*}$ & $4.35 \pm 0.33^{*}$ & $3.71 \pm 0.17$ & $3.24 \pm 0.40^{*}$ \\
\hline A3 & $0.75 \pm 0.17^{*}$ & $9.91 \pm 0.27^{*}$ & $3.73 \pm 0.11^{*}$ & $7.42 \pm 0.31^{*}$ & $9.68 \pm 0.18^{*}$ & $3.40 \pm 0.20^{*}$ \\
\hline A4 & $0.95 \pm 0.13^{*}$ & $4.72 \pm 0.17^{*}$ & $15.15 \pm 0.18^{*}$ & $4.71 \pm 0.07^{*}$ & $11.02 \pm 0.13^{*}$ & $4.34 \pm 0.13^{*}$ \\
\hline A5 & 0.00 & $10.22 \pm 0.20^{*}$ & $11.16 \pm 0.11^{*}$ & $4.89 \pm 0.11^{*}$ & $5.14 \pm 0.34^{*}$ & $3.19 \pm 0.31^{*}$ \\
\hline A6 & 0.00 & $1.86 \pm 0.31^{*}$ & $12.71 \pm 0.17^{*}$ & $6.07 \pm 0.10^{*}$ & $12.27 \pm 0.34^{*}$ & $2.54 \pm 0.20$ \\
\hline A7 & $0.02 \pm 0.14$ & $3.95 \pm 0.38^{*}$ & $5.21 \pm 0.06^{*}$ & $3.01 \pm 0.33^{*}$ & $6.73 \pm 0.24^{*}$ & $2.67 \pm 0.28^{*}$ \\
\hline A8 & $0.03 \pm 0.17$ & $3.49 \pm 0.35^{*}$ & $2.80 \pm 0.14^{*}$ & $1.43 \pm 0.33^{*}$ & $4.05 \pm 0.31^{*}$ & $2.81 \pm 0.24^{*}$ \\
\hline A9 & 0.00 & $4.06 \pm 0.13^{*}$ & $8.05 \pm 0.20^{*}$ & $2.93 \pm 0.30^{*}$ & $8.26 \pm 0.35^{*}$ & $2.81 \pm 0.16^{*}$ \\
\hline $\mathrm{A} 10$ & 0.00 & $6.91 \pm 0.17^{*}$ & $14.18 \pm 0.13^{*}$ & $8.50 \pm 0.14^{*}$ & $8.25 \pm 0.23^{*}$ & $3.14 \pm 0.27^{*}$ \\
\hline A11 & 0.00 & $2.69 \pm 0.11^{*}$ & $5.19 \pm 0.21^{*}$ & $4.30 \pm 0.20^{*}$ & $13.26 \pm 0.13^{*}$ & $2.58 \pm 0.14$ \\
\hline $\mathrm{p}$-value & 0.029 & 0.012 & 0.011 & 0.012 & 0.011 & 0.021 \\
\hline
\end{tabular}

Results are expressed as mean value \pm SD. Values marked with * within column are significantly different $(\mathrm{p}<0.05)$ from the control sample (induction time of pure extra virgin olive oil $=10.43 \mathrm{~h}$; induction time of extra virgin olive oil with mechanically homogenized microemulsion $=9.41 \mathrm{~h}$; induction time of extra virgin olive oil with ultrasonically homogenized microemulsion $=13.28 \mathrm{~h}$; induction time of extra virgin olive oil with liposomes $=6.98 \mathrm{~h}$ ) compared by Kruskal-Wallis test.

$\mathrm{A} 0=$ Untreated (fresh) sample; $\mathrm{AP}=$ pasteurized sample; $\mathrm{AL}=$ freeze-dried (lyophilized) sample; A1-A11 = ultrasound treated samples (see Table 1).

cooking oils which is characteristic for the Mediterranean diet. The effect of different blueberry phenolic extracts on the oxidative stability of extra virgin olive oil is shown in Table 4 . The highest prolongation of the oxidative stability of olive oil was achieved with extracts $\mathrm{A} 2$ and $\mathrm{A} 4$, obtained after treatment with high intensity ultrasound $(p=0.029)$. Interestingly, many extracts did not show any effect on the prolongation of the oxidative stability of the olive oil. Despite significant reduction of phenolic content in the pasteurized sample, its detected antioxidant capacity expressed through the effect on the prolongation of the oil oxidative stability may be due to the formation of anthocyanin polymers or formation of Maillard reaction products in response to thermal treatment [Brownmiller et al., 2008; Casati et al., 2017]. There are some speculations about the correlation between the TPC and the prolongation of the oxidative stability [Tiveron et al., 2012].

Blueberry extracts encapsulated in microemulsions prepared by mechanical homogenization ensured a significant prolongation of the oxidative stability of extra virgin olive oil (Table 4). In comparison to the control sample (oil enriched only with mechanically homogenized microemulsions), it was observed that olive oil needed 9.41 hours to oxidize, while the olive oil containing phenolic compounds encapsulated in ME-1 and ME-2 needed on average 13.94 hours and 13.46 hours, which meant prolongation by $48.22 \%$ and $43.09 \%$ ( $\mathrm{p}=0.012$ ), respectively. The microemulsions prepared with an ultrasonic homog- enizer generally showed a higher effect on the prolongation of the lag phase of the oxidative stability in comparison with microemulsions prepared with a mechanical homogenizer (Table 4). The prolongation of the lag phase was minimally $20.86 \%$ and maximally $114.08 \%$ for ME- $1 \quad(p=0.011)$ enriched with phenolic extracts. For ME-2 enriched with phenolic extracts, the prolongation rate varied from 27.94 to $99.85 \%$ $(p=0.011)$. The effect of liposome-phenolic extract systems on the prolongation of the oil oxidative stability was also very high and the average prolongation rate was $43.68 \%(\mathrm{p}=0.021)$ (Table 4). Microemulsions prepared with high pressure homogenizer and enriched with phenolic extracts had no effect on the prolongation of the oxidative stability of extra virgin olive oil (data not shown). Although Fernandez-Avila \& Trujillo [2017] stated that the use of high pressure homogenization produced the emulsion with better physical stability during storage, maintaining optimal oxidative stability until 3 months, this study did not prove the effect of microemulsions produced by high pressure homogenization on the prolongation of the oxidative stability of the extra virgin olive oil.

To the best of our knowledge, there are no previous data on the use of blueberry phenolic extracts encapsulated in microemulsions and liposomes on the prolongation of the oxidative stability of edible oils. Mohideen et al. [2015] studied the effects of blueberry juices on lipid oxidation during spray drying of menhaden oil and they found that $10 \%$ of blueberry juices 
reduced lipid oxidation. Li et al. [2015] reported that blueberry extract can be successfully used to delay the lipid oxidation during spray drying and the storage of Pollock liver oil. Although it was expected, a correlation between a lower droplet size of ME-2 and a better antioxidant effect of incorporated blueberry extracts than in the case of ME-1 was not found. This indicates that olive oil portion as the main difference in composition between ME-1 and ME-2 could contribute to the final physical properties of the produced emulsion due to its own phenolic content [Giacintucci et al., 2016]. Since the stronger effect on the prolongation of the lag phase of the oxidative stability of microemulsions produced by ultrasound homogenizer in comparison with microemulsions prepared with a mechanical homogenizer cannot be explained by differences in their droplet characteristics, this phenomenon merits further elucidation through investigation on added phenolic extracts partitioning and interface organization induced by these methods. Comparing two delivery systems in our study it was concluded that emulsions gave better results than liposomes. This could be explained by the fact that encapsulated phenolics also protect liposomal phospholipids from peroxidation, through acting as high-level scavengers of radicals [Balanč et al., 2015], as confirmed in the case of resveratrol, rutin, and quercetin encapsulation in liposomes via inhibition of malondialdehyde formation [Balanč et al., 2015; Cesquini et al., 2003]. In that sense, the antioxidant capacity of phenolics is probably partially involved in the anti-peroxidation of phospholipids, not only its action on olive oil, while in the case of microemulsions their antioxidant potential could be fully engaged in prolonging the oxidative stability of the olive oil.

\section{CONCLUSIONS}

The present study indicates that the use of freeze drying enhances the phenolic yield in extracts from blueberry fruits in comparison with raw plant material. Influence of high-intensity ultrasound on phenolic compounds was minimal while pasteurization caused significant losses. The most abundant phenolic constituents detected via HPLC analysis in all samples were malvidin glycosides.

The obtained results showed that the use of microemulsions and liposome systems can greatly enhance the effect of blueberry phenolic extracts on the prolongation of the oxidation process of extra virgin olive oil. The effect of native blueberry phenolic extracts on the prolongation of the oxidative stability of olive oil was very weak in comparison with the effect of extracts encapsulated in microemulsions and liposomes. Furthermore, the microemulsions prepared by an ultrasound homogenizer showed a higher effect on the prolongation of the oxidative stability than microemulsions prepared with mechanical and high pressure homogenizer. Accordingly, encapsulated natural antioxidants from blueberry may be considered as potential candidates for preserving the oxidative stability of lipid-containing food.

\section{RESEARCH FUNDING}

The authors are grateful to the Ministry of Science and Technology of the Republic of Croatia and the Minis- try of Education, Science and Technological Development of the Republic of Serbia for having financed bilateral project entitled "Enhancement of the stability and the bioavailability of selected phytochemicals using different delivery systems and mathematical modelling of an in vitro digestion model".

\section{ACKNOWLEDGEMENTS}

The authors would like to thank Dr. Robert Belužić from the Department of Molecular Medicine from the Rudjer Boskovic Institute in Zagreb (Croatia) for the technical help using the high pressure homogenization.

\section{CONFLICT OF INTERESTS}

The authors declare that they have no conflict of interest.

\section{REFERENCES}

1. Afrin, S., Gasparrini, M., Forbes-Hernandez, T.Y., Reboredo-Rodriguez, P., Mezzetti, B., Varela-Lopez, A., Giampieri, F., Battino, M. (2016). Promising health benefits of the strawberry: A focus on clinical studies. Journal of Agricultural and Food Chemistry, 64(22), 4435-4449.

2. Aladedunye, F., Przybylski, R., Niehaus, K., Bednarz, H., Matthäus, B. (2014). Phenolic extracts from Crataegus $\times$ mordenensis and Prunus virginiana: Composition, antioxidant activity and performance in sunflower oil. LWT - Food Science and Technology, 59(1), 308-319.

3. Asnaashari, M., Tajik, R., Khodaparast, M.H.H. (2015). Antioxidant activity of raspberry (Rubus fruticosus) leaves extract and its effect on oxidative stability of sunflower oil. Journal of Food Science and Technology - Mysore, 52(8), 5180-5187.

4. Balanč, B.D., Ota, A., Djordjević, V.B., Šentjurc, M., Nedović, V.A., Bugarski, B.M., Ulrih, N.P. (2015). Resveratrol-loaded liposomes: interaction of resveratrol with phospholipids. European Journal of Lipid Science and Technology, 117(10), 1615-1626.

5. Barba, F.J., Mariutti, L.R.B., Bragagnolo, N., Mercadante, A.Z., Barbosa-Cánovas, G.V., Orlien, V. (2017). Bioaccessibility of bioactive compounds from fruits and vegetables after thermal and nonthermal processing. Trends in Food Science \& Technology, 67(September), 195-206.

6. Basu, A., Lyons, T.J. (2012). Strawberries, blueberries, and cranberries in the metabolic syndrome: Clinical perspectives. Journal of Agricultural and Food Chemistry, 60(23), 5687-5692.

7. Brownmiller, C., Howard, L.R., Prior, R.L. (2008). Processing and storage effects on monomeric anthocyanins, percent polymeric color, and antioxidant capacity of processed blueberry products. Journal of Food Science, 73(5), H72-H79.

8. Casati, C.B., Baeza, R., Sanchez, V. (2017). Comparison of the kinetics of monomeric anthocyanins loss and colour changes in thermally treated Blackcurrant, Maqui Berry and Blueberry pulps from Argentina. Journal of Berry Research, 7(2), 85-96.

9. Cesquini, M., Torsoni, M.A., Stoppa, G.R., Ogo, S.H. (2003). t-BOOH-induced oxidative damage in sickle red blood cells and the role of flavonoids. Biomedicine \& Pharmacotherapy, 57(3-4), 124-129.

10. Chatzidaki, M.D., Mitsou, E., Yaghmur, A., Xenakis, A., Papadimitriou, V. (2015). Formulation and characterization of food- 
grade microemulsions as carriers of natural phenolic antioxidants. Colloids and Surfaces A: Physicochemical and Engineering Aspects, 483(October), 130-136.

11. Dragović-Uzelac, V., Savić, Z., Brala, A., Levaj, B., Kovačević, D.B., Biško, A. (2010). Evaluation of phenolic content and antioxidant capacity of blueberry cultivars (Vaccinium corymbosum L.) grown in the northwest Croatia. Food Technology and Biotechnology, 48(2), 214-221.

12. Drvenica, I., Đorđević, V., Trifković, K., Bojana, B., Steva, L., Bugarski, B., Nedović, V. (2017). Industry-Relevant Encapsulation Technologies for Food and Functional Food Production. In M. Krokida (Ed.), Thermal and Nonthermal Encapsulation Methods (1st edition, pp. 221-263). Boca Raton, Florida: CRC Press.

13. Eicke, H.F., Borkovec, M., Das-Gupta, B. (1989). Conductivity of water-in-oil microemulsions: a quantitative charge fluctuation model. The Journal of Physical Chemistry, 93(1), 314-317.

14. Fernandez-Avila, C., Trujillo, A.J. (2017). Enhanced stability of emulsions treated by Ultra-High Pressure Homogenization for delivering conjugated linoleic acid in Caco-2 cells. Food $\mathrm{Hy}$ drocolloids, 71(October), 271-281.

15. Giacintucci, V., Di Mattia, C., Sacchetti, G., Neri, L., Pittia, P. (2016). Role of olive oil phenolics in physical properties and stability of mayonnaise-like emulsions. Food Chemistry, 213(December), 369-377.

16. Giampieri, F., Forbes-Hernandez, T.Y., Gasparrini, M., Afrin, S., Cianciosi, D., Reboredo-Rodriguez, P., Varela Lopez, A., Quiles, J.L., Mezzetti, B., Battino, M. (2017). The healthy effects of strawberry bioactive compounds on molecular pathways related to chronic diseases. Annals of the New York Academy of Sciences, 1398(1), 62-71.

17. Gibis, M., Vogt, E., Weiss, J. (2012). Encapsulation of polyphenolic grape seed extract in polymer-coated liposomes. Food \& Function, 3(3), 246-254.

18. Gibis, M., Zeeb, B., Weiss, J. (2014). Formation, characterization, and stability of encapsulated hibiscus extract in multilayered liposomes. Food Hydrocolloids, 38(July), 28-39.

19. Golmohamadi, A., Möller, G., Powers, J., Nindo, C. (2013). Effect of ultrasound frequency on antioxidant activity, total phenolic and anthocyanin content of red raspberry puree. Ultrasonics Sonochemistry, 20(5), 1316-1323.

20. Gómez-Mascaraque, L.G., Casagrande Sipoli, C., de La Torre, L.G., López-Rubio, A. (2017). Microencapsulation structures based on protein-coated liposomes obtained through electrospraying for the stabilization and improved bioaccessibility of curcumin. Food Chemistry, 233(October), 343-350.

21. Gortzi, O., Lalas, S., Chinou, I., Tsaknis, J. (2008). Reevaluation of bioactivity and antioxidant activity of Myrtus communis extract before and after encapsulation in liposomes. European Food Research and Technology, 226(3), 583-590.

22. Haminiuk, C.W.I., Maciel, G.M., Plata-Oviedo, M.S.V., Peralta, R.M. (2012). Phenolic compounds in fruits - an overview. International Journal of Food Science and Technology, 47(10), 2023-2044 .

23. Helrich, K. (1990). Official Methods of Analysis: 930.04 Moisture Content in Plants (15th editi, Vol. 1). Arlington, Virginia, USA: AOAC.

24. Howard, L.R., Brownmiller, C., Mauromoustakos, A., Prior, R.L. (2016). Improved stability of blueberry juice anthocyanins by acidification and refrigeration. Journal of Berry Research, 6(2), 189-201.

25. Huang, H., Chen, G., Liao, D., Zhu, Y., Xue, X. (2016). Effects of berries consumption on cardiovascular risk factors: a metaanalysis with trial sequential analysis of randomized controlled trials. Scientific Reports, 6(March), 23625.

26. Isailović, B.D., Kostić, I.T., Zvonar, A., Đordević, V.B., Gašperlin, M., Nedović, V.A., Bugarski, B.M. (2013). Resveratrol loaded liposomes produced by different techniques. Innovative Food Science and Emerging Technologies, 19(July), 181-189.

27. Jafari, S.M., He, Y., Bhandari, B. (2006). Nano-emulsion production by sonication and microfluidization - A comparison. International Journal of Food Properties, 9(3), 475-485.

28. Juttulapa, M., Piriyaprasarth, S., Takeuchi, H., Sriamornsak, P. (2017). Effect of high-pressure homogenization on stability of emulsions containing zein and pectin. Asian Journal of Pharmaceutical Sciences, 12(1), 21-27.

29. Keinänen, M., Julkunen-Tiitto, R. (1996). Effect of sample preparation method on birch (Betula pendula Roth) leaf phenolics. Journal of Agricultural and Food Chemistry, 44(9), 2724-2727.

30. Li, J., Solval, K.M., Alfaro, L., Zhang, J., Chotiko, A., Delgado, J.L.B., Chouljenko, A., Bankston, D., Bechtel, P.J Sathivel, S. (2015). Effect of blueberry extract from blueberry pomace on the microencapsulated fish oil. Journal of Food Processing and Preservation, 39(2), 199-206.

31. Lu, W., Kelly, A.L., Miao, S. (2016). Emulsion-based encapsulation and delivery systems for polyphenols. Trends in Food Science \& Technology, 47(January), 1-9.

32. McClements, D.J. (2012). Nanoemulsions versus microemulsions: terminology, differences, and similarities. Soft Matter, 8(6), 1719-1729.

33. Michalska, A., Lysiak, G. (2015). Bioactive compounds of blueberries: Post-harvest factors influencing the nutritional value of products. International Journal of Molecular Sciences, 16(8), 18642-18663.

34. Mohideen, F.W., Stine, J., Bechtel, P.J., Solval, K.M., Bankston, J.D., Sathivel, S. (2015). Effects of blueberry (Vaccinium corymbosum) juice on lipid oxidation during spray drying of microencapsulated menhaden Oil. International Journal of Food Properties, 18(5), 1139-1153.

35. Može, Š., Polak, T., Gašperlin, L., Koron, D., Vanzo, A., U1rih, N.P., Abram, V. (2011). Phenolics in Slovenian bilberries (Vaccinium myrtillus L.) and blueberries (Vaccinium corymbosum L.). Journal of Agricultural and Food Chemistry, 59(13), 6998-7004.

36. Neveu, V., Perez-Jiménez, J., Vos, F., Crespy, V., du Chaffaut, L., Mennen, L., Knox, C., Eisner, R., Cruz, J., Wishart, D., Scalbert, A. (2010). Phenol-Explorer: an online comprehensive database on polyphenol contents in foods. Database, art. no. bap024.

37. Nile, S.H., Park, S.W. (2014). Edible berries: Bioactive components and their effect on human health. Nutrition, 30(2), 134-144.

38. Pérez-Jiménez, J., Neveu, V., Vos, F., Scalbert, A. (2010). Identification of the 100 richest dietary sources of polyphenols: an application of the Phenol-Explorer database. European Journal of Clinical Nutrition, 64(Suppl 3), S112-S120.

39. Perrett, S., Golding, M., Williams, W.P. (1991). A simple method for the preparation of liposomes for pharmaceutical applications: Characterization of the liposomes. Journal of Pharmacy and Pharmacology, 43(3), 154-161. 
40. Pravilovic, R., Radunovic, V., Boskovic-Vragolovic, N., Bugarski, B., Pjanovic, R. (2015). The influence of membrane composition on the release of polyphenols from liposomes. Hemijska Industrija, 69(4), 347-353.

41. Rashidinejad, A., Birch, E.J., Sun-Waterhouse, D., Everett, D.W. (2014). Delivery of green tea catechin and epigallocatechin gallate in liposomes incorporated into low-fat hard cheese. Food Chemistry, 156(August), 176-183.

42. Rodríguez-Mateos, A., Cifuentes-Gomez, T., Tabatabaee S., Lecras, C., Spencer, J.P. E. (2012). Procyanidin, anthocyanin and chlorogenic acid contents of highbush and lowbush blueberries. Journal of Agricultural and Food Chemistry, 60(23), 5772-5778.

43. Sablani, S.S., Andrews, P.K., Davies, N.M., Walters, T., Saez, H., Bastarrachea, L. (2011). Effects of air and freeze drying on phytochemical content of conventional and organic berries. Drying Technology, 29(11), 205-216.

44. Singleton, V.L., Rossi, J.A.J. (1965). Colorimetry of total phenolics with phosphomolybdic-phosphotungstic acid reagents. American Journal of Enology and Viticulture, 16(3), 144-158.
45. Tiveron, A.P., Melo, P.S., Bergamaschi, K.B., Vieira, T.M.F.S., Regitano-d'Arce, M.A.B., Alencar, S.M. (2012). Antioxidant activity of brazilian vegetables and its relation with phenolic composition. International Journal of Molecular Sciences, 13(7), 8943-8957.

46. Xu, S., Ni, Z., Ma, L., Zheng, X. (2017). Control of alternaria rot of cherry tomatoes by food-grade Laurus nobilis essential oil microemulsion. Journal of Food Safety, 37(1), e12286.

47. Zorić, Z., Dragović-Uzelac, V., Pedisić, S., Kurtanjek, Ž., Garofulić, I.E. (2014). Kinetics of the degradation of anthocyanins, phenolic acids and flavonols during heat treatments of freeze-dried sour cherry Marasca paste. Food Technology and Biotechnology, 52(1), SI, 101-108.

Submitted: 6 May 2018. Revised: 13 August 2018. Accepted: 17 October 2018. Published on-line: 3 December 2018. 
